\title{
Cardiovascular Complications of Acute Amphetamine Abuse Cross-sectional study
}

Elham Bazmi, ${ }^{1}$ Farinaz Mousavi, ${ }^{1}$ Leila Giahchin, ${ }^{1}$ Tahmineh Mokhtari, ${ }^{2}$ Behnam Behnoush ${ }^{3}$

$$
\text { مضاعفات القلب والأوعية الدموية النابجة عن إساعة تعاطي منبهات الأمفيتامين }
$$

إلهام بازمي، فاريناز موسافي، ليلى جياشن، تهمينة مختاري، بهنام بهنوش

ABSTRACT: Objectives: This study aimed to evaluate cardiovascular complications among patients who abuse amphetamines. Methods: This cross-sectional study took place between April 2014 and April 2015 among 3,870 patients referred to the Toxicology Emergency Department of Baharlou Hospital, Tehran University of Medical Sciences, Tehran, Iran. Those with clinical signs of drug abuse and positive urine screening tests were included in the study, while cases of chronic abuse were excluded. Cardiac complications were evaluated via electrocardiography (ECG) and transthoracic echocardiography. Results: A total of 230 patients (5.9\%) had a history of acute amphetamine abuse and positive urine tests. Of these, 32 patients $(13.9 \%)$ were $<20$ years old and $196(85.2 \%)$ were male. In total, 119 (51.7\%) used amphetamine and methamphetamine compounds while 111 (48.3\%) used amphetamines with morphine or benzodiazepines. The most common ECG finding was sinus tachycardia (43.0\%), followed by sinus tachycardia plus a prolonged QT interval (34.3\%). Mean creatine kinase-MB and troponin I levels were $35.9 \pm 4.3 \mathrm{U} / \mathrm{mL}$ and $0.6 \pm 0.2 \mathrm{ng} / \mathrm{mL}$, respectively. A total of 60 patients (26.1\%) were admitted to the Intensive Care Unit. The majority $(83.3 \%)$ of these patients had normal echocardiography results. The mean aortic root diameter (ARD) was $27.2 \pm 2.8 \mathrm{~mm}$. Abnormalities related to the ARD were found in 10 patients (16.7\%), three of whom subsequently died. Conclusion: According to these findings, cardiac complications were common among Iranian patients who abuse amphetamines, although the majority of patients had normal echocardiography and ECG findings.

Keywords: Amphetamines; Substance Abuse; Cardiovascular Abnormalities; Tachycardia; Echocardiography; Electrocardiography; Iran.

الملخص: الهدف: هدفت هذه الدراسة إلى تقييم مضاعفات جهاز القلب والأوعية الدموية لدى الدرئ الدرضى الدرئ الذين يتعاطون الأمفيتامينات.

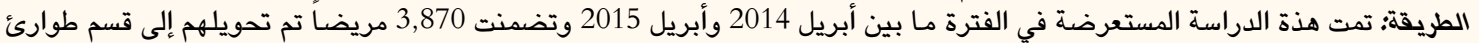

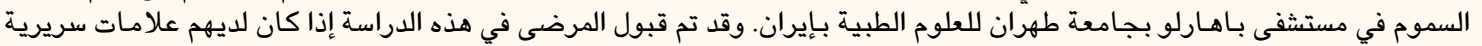

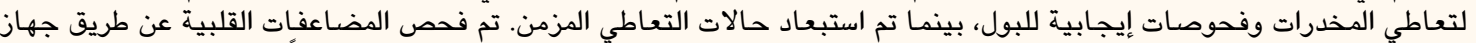

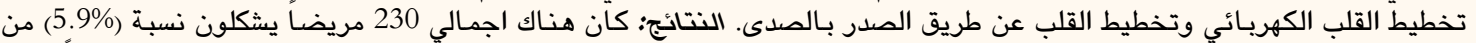

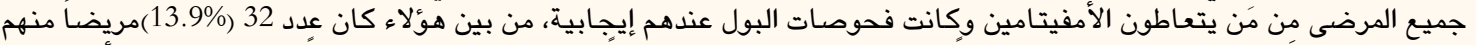

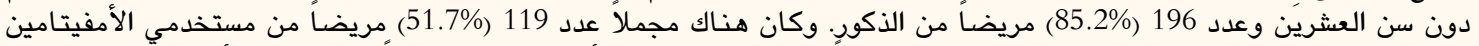

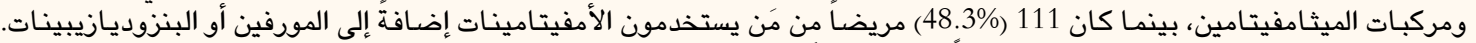

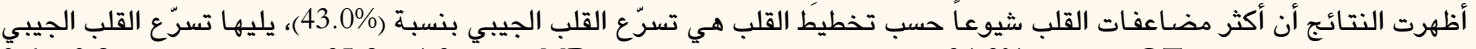

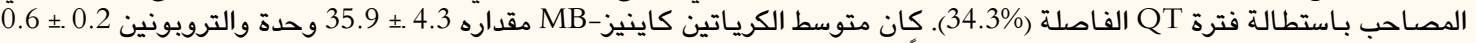

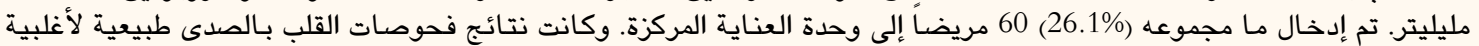

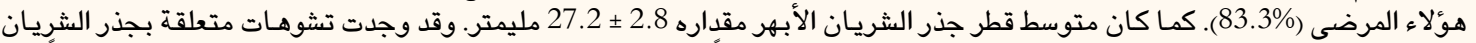

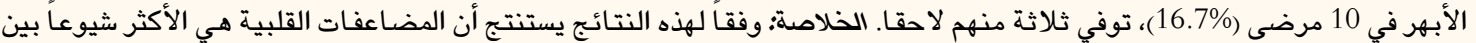

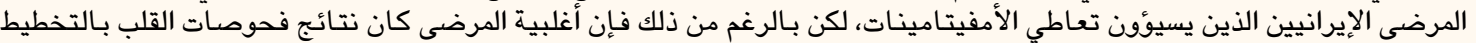
الكهريائي ويالصدى الإيراين الذندهم طبيعية.

الكلمات المفتاحية: الأمفيتامينات؛ تعاطي المواد الكيميائية؛ تشوهـات القلب والأوعية الدموية؛ تسرّع دقات القلب؛ تخطيط القلب بالصدى؛ تخطيط القلب الكهربائي؛ إيران.

\section{Advances in KNOWledge}

Among Iranian patients, the most common cardiac abnormality following acute amphetamine abuse was sinus tachycardia followed by sinus tachycardia plus prolonged QT intervals.

\section{Application to Patient Care}

The findings of this study may be used by emergency physicians to increase awareness of the potential cardiovascular complications of acute amphetamine abuse. 
$\mathrm{P}$ SYCHOACTIVE DRUG DEPENDENCE/ABUSE has become an increasing problem worldwide, with adverse physical, familial, social, mental and financial consequences. ${ }^{1}$ In Iran, patterns of drug abuse have changed immensely in recent years, with drug use shifting from traditional opioids to new artificial opioids. ${ }^{2}$ Moreover, the incidence of drug poisoning and toxicity due to the abuse of psychoactive drugs-such as amphetamines-has increased among younger individuals. ${ }^{3}$ Acute use of amphetamines results in increased brain activity and a feeling of euphoria; however, chronic use of these compounds can lead to psychological dependency, loss of appetite, depression, aggressive behaviour, irritability and sleep, memory and mood disorders. ${ }^{1}$ In addition, amphetamine abuse may lead to increased stimulation of the sympathetic nervous system, which could in turn lead to hypertension, hyperthermia, subarachnoid haemorrhage and ventricular dysrhythmias, sometimes resulting in death. ${ }^{4}$

Depending on the type and form of the drug, central nervous system stimulants can be imbibed orally, injected, smoked or snorted. Direct injection of the stimulant into the blood stream or inhalation into the lungs enables the more rapid onset of the drug's effects. ${ }^{5}$ The stimulants increase the synaptic concentration of neural mediators (especially adrenaline, dopamine and serotonin), stimulating these mediators and inhibiting their reuptake. Amphetamine compounds stimulate the central and peripheral nervous systems, increasing catecholamine secretion and inhibiting their reuptake. At the synapse, the catecholamines lead to excessive cardiac stimulation and an increased heart rate. ${ }^{1}$ Amphetamine compounds have good oral absorption and a wide range of distribution sizes $(3-33 \mathrm{~L} / \mathrm{kg})$; they are primarily metabolised by the liver and excreted in acidic urine. ${ }^{1}$

Cardiac complications are an important issue in the context of drug toxicity. Hypertension is the most common cardiovascular result of central nervous system stimulants. ${ }^{1}$ With oral amphetamines, systolic and diastolic blood pressure increases, while heart rate decreases. The cardiovascular effect of the laevus isomer in amphetamines is greater than that of the dexter isomer. ${ }^{6}$ Chest pains, dysrhythmias, acute coronary syndrome, acute cardiac infarctions, vasospasms, irreversible cardiomyopathy and acute pulmonary oedema are among the cardiovascular manifestations of toxicity arising from psychoactive drugs. ${ }^{7}$ This study aimed to evaluate cardiovascular complications among Iranian patients who abuse amphetamines.

\section{Methods}

This descriptive cross-sectional study took place between April 2014 and April 2015 among 3,870 patients referred to the Toxicology Emergency Department of Baharlou Hospital, Tehran University of Medical Sciences, Tehran, Iran. Only those individuals with positive urine drug screening test results and a history of acute amphetamine abuse were included in the study. Patients with a history of underlying cardiovascular disease or a family history of cardiac disease and those with diabetes mellitus, proven hypertension or hyperlipidaemia were excluded from the study. In addition, chronic drug users without any evidence of recent abuse were not included.

A predesigned checklist was used to collect existing data, including the demographic characteristics and laboratory and clinical findings of the patients. Rapid urine drug screening tests (ACON Laboratories Inc., San Diego, California, USA) were performed. Following this, blood samples were taken from each patient. Patients were evaluated using cardiac and vital sign monitoring, routine laboratory examinations and cardiac biomarker tests, including levels of troponin I (AiA-360 benchtop immunoassay analyser, Tosoh Bioscience, San Francisco, California, USA) and creatinine kinase (CK)-MB (Architect System STAT CK-MB chemiluminescent microparticle immunoassay, Abbott Diagnostics, Wiesbaden, Germany). Normal cut-off troponin I and CK-MB levels were set at $0.1 \mathrm{ng} / \mathrm{mL}$ and $24.0 \mathrm{U} / \mathrm{mL}$ respectively, as per the manufacturers' recommendations.

Cardiac complications were evaluated via electrocardiography (ECG) and transthoracic echocardiography (TTE). All ECG and TTE scans were performed by an emergency physician. Each patient underwent three ECG recordings to measure the following variables: heart rate, rhythm, QT interval (intervals of $>0.44$ milliseconds were considered prolonged), supraventricular and ventricular arrhythmias, atrioventricular and ventricular cardiac blocks, tall T-waves and myocardial ischaemia (i.e. ST segment and T-wave changes). ${ }^{8}$ Tachycardia was defined as a heart rate of $>100$ beats/minute. ${ }^{1}$ Moreover, for patients admitted to the Intensive Care Unit (ICU) due to tachycardia or very abnormal ECG findings, additional echocardiography was performed to measure their ejection fraction (EF), regional wall motion abnormalities, aortic root diameter (ARD), cardiac wall size (including right ventricular enddiastolic volume, left ventricle end-systolic volume, left ventricular end-diastolic volume, left ventricular 
Table 1: Characteristics of patients referred to a toxicology emergency department following acute amphetamine abuse in Tehran, Iran $(\mathrm{N}=230)$

$\begin{array}{lc}\text { Characteristic } & \mathbf{n}(\%) \\ \text { Age in years } & \\ <20 & 32(13.9) \\ 21-30 & 86(37.4) \\ 31-40 & 62(27.0) \\ 41-50 & 33(14.3) \\ >50 & 17(7.4) \\ \text { Gender } & \\ \text { Male } & 196(85.2) \\ \text { Female } & 34(8.7) \\ \text { Drugs taken } & \\ \text { Amphetamine and methamphetamine } & 119(51.7) \\ \text { Amphetamine and morphine/benzodiazepines } & 111(48.3) \\ \text { Method of drug administration } & \\ \text { Smoking } & 161(70.0) \\ \text { Oral } & 20(8.7) \\ \text { Injection } & 10(4.3) \\ \text { Combination } & 39(17.0)\end{array}$

Time to admission in hours

$0-6$

$>6$

Agitation

Present

Absent

ECG finding*

Normal

Sinus tachycardia

Sinus tachycardia plus prolonged QT interval

Arrhythmia

Arrhythmia plus first-degree atrioventricular block

Tall T-wave

Arrhythmia, ST segment elevation plus anterior MI

Arrhythmia plus ST segment elevation

ST segment elevation

Anterior MI

Mean $\mathrm{BP} \pm \mathrm{SD}$

Systolic BP in mmHg

Diastolic BP in $\mathrm{mmHg}$

$\begin{array}{lc}\text { Mean HR in beats/minute } & 109.1 \pm 9.3 \\ \text { Mean CK-MB level in U/mL } & 35.9 \pm 4.3 \\ \text { Mean troponin I level in } \mathrm{ng} / \mathrm{mL} & 0.6 \pm 0.2\end{array}$

$E C G=$ electrocardiography; $M I=$ myocardial infarction $; B P=$ blood pressure; $S D=$ standard deviation; $H R=$ heart rate; $C K-M B=$ creatinine kinase- $M B$.

"Patients with more than one abnormality have been included in several categories.

end-diastolic pressure [LVEDP], left ventricular enddiastolic diameter [LVEDD] and left ventricle endsystolic diameter [LVESD]) and other abnormalities.

Data were analysed using the Statistical Package for the Social Sciences (SPSS), Version 22 (IBM Corp., Chicago, Illinois, USA). Chi-squared, analysis of variance, Student's t-test, Mann-Whitney U and Kruskal-Wallis tests were performed, as appropriate. A $P$ value of $<0.050$ was considered statistically significant. Interquartile ranges and correlations were also calculated.

Ethical approval for this study was granted by the Tehran University of Medical Sciences. Prior to being enrolled in the study, all of the patients gave conscious informed consent. If the competency of the patient was in doubt, informed consent was given by a relative. Data confidentiality and security were ensured throughout the study period.

\section{Results}

Of the 3,870 patients referred to the Toxicology Emergency Department during the study period, 460 (11.9\%) had a history of amphetamine use. Among these, 395 cases (10.2\%) had positive urine drug screening results; however, 165 cases (4.3\%) were excluded due to a history of chronic abuse. Therefore, a total of 230 patients (5.9\%) were enrolled in the study. The mean age of the participants was $34.4 \pm 11.4$ years (range: $15-68$ years old) and the majority were male (85.2\%). Amphetamines were smoked by 161 patients (70.0\%), taken orally by 20 patients $(8.7 \%)$, injected by 10 patients $(4.3 \%)$ and taken via a combination of methods by 39 patients (17.0\%). A total of 119 patients (51.7\%) used amphetamines in combination with methamphetamine compounds while 111 (48.3\%) used amphetamines with morphine or benzodiazepines. The referral time to the emergency ward was $\leq 6$ hours of use for 174 patients $(75.7 \%)$ and $>6$ hours of use for 56 patients (24.3\%) [Table 1].

The ECG results were normal for 104 patients (45.2\%). Sinus tachycardia was observed in 99 patients (43.0\%), while $34.3 \%$ of patients had sinus tachycardia plus a prolonged QT interval. Arrhythmias were 
Table 2: Selected echocardiographic measurements according to age group among patients admitted to an intensive care unit following acute amphetamine abuse in Tehran, Iran $(\mathrm{N}=60)$

\begin{tabular}{|c|c|c|c|c|c|c|}
\hline \multirow[t]{2}{*}{ Mean \pm SD } & \multicolumn{5}{|c|}{ Age in years } & \multirow[t]{2}{*}{$P$ value } \\
\hline & $\begin{array}{c}<20 \\
(n=6)\end{array}$ & $\begin{array}{c}21-30 \\
(\mathrm{n}=17)\end{array}$ & $\begin{array}{c}31-40 \\
(n=15)\end{array}$ & $\begin{array}{l}41-50 \\
(n=5)\end{array}$ & $\begin{array}{c}>50 \\
(\mathrm{n}=17)\end{array}$ & \\
\hline RVESv in $\mathrm{mL} / \mathrm{m}^{2}$ & $24.3 \pm 3.2$ & $25.1 \pm 3.4$ & $28.1 \pm 3.4$ & $26.6 \pm 3.5$ & $26.2 \pm 3.7$ & 0.144 \\
\hline LVEDD in $\mathrm{mm}$ & $43.2 \pm 4.4$ & $43.5 \pm 4.3$ & $46.6 \pm 4.5$ & $43.8 \pm 4.6$ & $47.7 \pm 4.7$ & 0.034 \\
\hline LVESD in $\mathrm{mm}$ & $28.8 \pm 3.2$ & $29.8 \pm 3.4$ & $29.1 \pm 3.6$ & $30.4 \pm 3.5$ & $28.6 \pm 3.7$ & 0.433 \\
\hline EF in \% & $54.2 \pm 5.8$ & $50.6 \pm 5.6$ & $48.2 \pm 5.5$ & $50.1 \pm 5.5$ & $48.8 \pm 5.2$ & 0.012 \\
\hline LVEDP in $\mathrm{mmHg}$ & $8.8 \pm 3.4$ & $8.3 \pm 3.7$ & $8.4 \pm 3.5$ & $8.4 \pm 3.2$ & $8.8 \pm 3.5$ & 0.042 \\
\hline ARD in $\mathrm{mm}$ & $24.8 \pm 2.4$ & $26.3 \pm 2.7$ & $25.7 \pm 2.6$ & $28.8 \pm 2.9$ & $29.7 \pm 3.3$ & 0.032 \\
\hline
\end{tabular}

$S D=$ standard deviation; $R V E S v=$ right ventricle end-systolic volume; $L V E D D=$ left ventricular end-diastolic diameter; $L V E S D=$ left ventricle endsystolic diameter; $E F=$ ejection fraction; $L V E D P=$ left ventricular end-diastolic pressure; $A R D=$ aortic root diameter.

observed in eight patients (3.5\%). Other cardiac abnormalities included arrhythmias plus a first-degree atrioventricular block (2.6\%), tall T-waves (1.7\%), arrhythmias, ST segment elevation plus anterior myocardial infarctions (1.7\%), arrhythmias plus ST segment elevation (1.3\%), anterior myocardial infarctions (0.4\%) and ST segment elevation (0.4\%). Mean CK-MB and troponin I levels were $35.9 \pm 4.3 \mathrm{U} / \mathrm{mL}$ and $0.6 \pm 0.2 \mathrm{ng} / \mathrm{mL}$, respectively [Table 1]. For the

Table 3: Cardiac function according to echocardiography among patients admitted to an intensive care unit following acute amphetamine abuse in Tehran, $\operatorname{Iran}(\mathrm{N}=60)$

\begin{tabular}{lc} 
Finding & n (\%) \\
Normal & $50(83.3)$ \\
LVS or LVD dysfunction alone & $5(8.3)$ \\
LVS and LVD dysfunction combined & $1(1.7)$ \\
Anterior akinaesia & $3(5.0)$ \\
PAH plus cor pulmonale & $1(1.7)$ \\
RV function & \\
Normal & $58(96.7)$ \\
Abnormal & $2(3.3)$ \\
MV dysfunction & \\
Normal & \\
Mild regurgitation & $43(71.7)$ \\
Moderate regurgitation & $13(21.7)$ \\
Prolapse & $2(3.3)$ \\
Other valvular dysfunctions & $2(3.3)$ \\
None & \\
Micuspid regurgitation & \\
\hline
\end{tabular}

patients with arrhythmias, this complication was followed by ventricular tachycardia, premature atrial contractions, paroxysmal supraventricular tachycardia and premature ventricular contractions.

A total of 60 patients were admitted to the ICU; of these, the majority were $21-30$ years old (28.3\%). Mean LVEDD and LVESD measurements were $45.4 \pm 4.4 \mathrm{~mm}$ (range: $39-56 \mathrm{~mm}$ ) and $29.2 \pm 3.5 \mathrm{~mm}$ (range: 22-36 $\mathrm{mm}$ ), respectively. Mean LVEDD measurements were significantly higher in patients who were $>50$ years old $(P=0.034)$. Although there was no significant difference in LVESD measurements among age groups $(P=0.433)$, the highest value was observed in patients between $41-50$ years old. The mean LVEDP value was $8.5 \pm 3.5 \mathrm{mmHg}$ (range: 6-10 $\mathrm{mmHg}$ ) and there was a significant difference in LVEDP value according to age group $(P=0.042)$, with the highest values noted in patients $<20$ years old and $>50$ years old. The highest mean EF was observed in patients $<20$ years old and the lowest mean EF was found in patients aged $31-40$ years old $(P=0.012)$. The mean ARD was $27.2 \pm 2.8 \mathrm{~mm}$ (range: $22-32 \mathrm{~mm}$ ) with a significant difference according to age group $(P=0.032)$. Patients $>50$ years of age had the highest mean ARD and patients $<20$ years old had the lowest mean ARD [Table 2].

Of the 60 patients admitted to the ICU, the majority had normal echocardiography findings (83.3\%). However, four patients (6.7\%) had left ventricular systolic and/or diastolic dysfunction. The most common abnormality of the cardiac valves was related to the mitral valve (MV); $21.7 \%$ of patients had mild MV regurgitation, 3.3\% had moderate MV regurgitation and 3.3\% had MV prolapse. Tricuspid regurgitation and mild aortic regurgitation were found in $3.3 \%$ and $1.7 \%$ of patients, respectively. Right ventricular function was abnormal in two patients (3.3\%). Anterior akinaesia and pulmonary hypertension plus cor pulmonale were each reported 
Table 4: Right ventricular wall mobility and function abnormalities according to age group among patients admitted to an intensive care unit following acute amphetamine abuse in Tehran, Iran $(\mathrm{N}=60)$

\begin{tabular}{lccccc}
\multicolumn{5}{c}{$\mathbf{n}(\%)$} \\
& \multicolumn{2}{c}{$\begin{array}{c}\text { Right ventricular wall } \\
\text { motion abnormalities }\end{array}$} & $\begin{array}{c}\text { Right ventricular } \\
\text { function }\end{array}$ \\
& Normal & Abnormal & Normal & Abnormal \\
Age in years & & & \\
$<20$ & $6(10.0)$ & $0(0.0)$ & $6(10.0)$ & $0(0.0)$ \\
$21-29$ & $17(28.3)$ & $0(0.0)$ & $17(28.3)$ & $0(0.0)$ \\
$30-39$ & $13(21.7)$ & $2(3.3)$ & $13(21.7)$ & $2(3.3)$ \\
$40-41$ & $5(8.3)$ & $0(0.0)$ & $5(8.3)$ & $0(0.0)$ \\
$>50$ & $16(26.7)$ & $1(1.7)$ & $17(28.3)$ & $0(0.0)$ \\
Total & $\mathbf{5 7 ( 9 5 . 0 )}$ & $\mathbf{3 ( 5 . 0 )}$ & $\mathbf{5 8}(\mathbf{9 6 . 7})$ & $\mathbf{2}(3.3)$
\end{tabular}

in $1.7 \%$ of patients, respectively [Table 3]. Right ventricular wall movement abnormalities was noted only among patients who were 30-39 years old and $>50$ years old. In addition, abnormal right ventricular function was seen only among those aged $30-39$ years old [Table 4].

Unfortunately, 10 patients (16.7\%) died among those admitted to the ICU. While left ventricular end-diastolic volume and diameter values were normal in all of the admitted patients, two living patients (3.3\%) and one deceased patient (1.7\%) had abnormal interventricular systolic diameters. Moreover, abnormal EF was noted in four of the patients who died (6.7\%) and three living patients (5.0\%), with abnormal EF significantly more prevalent among the deceased patients $(P=0.011)$. The ARD was abnormal in seven living patients and three deceased patients (11.7\% versus $5.0 \% ; P=0.211$ ) [Table 5]. The frequency of severe right ventricle end-diastolic volume disorder was higher among the deceased patients

Table 5: Echocardiographic findings among deceased and living patients admitted to an intensive care unit following acute amphetamine abuse in Tehran, Iran $(\mathrm{N}=60)$

\begin{tabular}{|c|c|c|c|}
\hline \multirow[t]{2}{*}{ Finding } & \multicolumn{2}{|c|}{ n (\%) } & \multirow[t]{2}{*}{$P$ value } \\
\hline & $\begin{array}{l}\text { Living } \\
\text { patients } \\
(n=50)\end{array}$ & $\begin{array}{c}\text { Deceased } \\
\text { patients } \\
(\mathbf{n}=10)\end{array}$ & \\
\hline LVEDv & $0(0.0)$ & $0(0.0)$ & - \\
\hline IVSD & $2(3.3)$ & $1(1.7)$ & 0.427 \\
\hline LVEDD & $0(0.0)$ & $0(0.0)$ & - \\
\hline Abnormal EF & $3(5.0)$ & $4(6.7)$ & 0.011 \\
\hline ARD & 7 (11.7) & $3(5.0)$ & 0.212 \\
\hline
\end{tabular}

Table 6: Frequency of right ventricle end-diastolic volume disorder among deceased and living patients admitted to an intensive care unit in Tehran, Iran, following acute amphetamine abuse $(\mathrm{N}=60)$

\begin{tabular}{lcc} 
Classification & \multicolumn{2}{c}{$\mathbf{n}(\mathbf{\%})$} \\
& $\begin{array}{l}\text { Living patients } \\
(\mathbf{n}=\mathbf{5 0})\end{array}$ & $\begin{array}{c}\text { Deceased patients } \\
(\mathbf{n}=\mathbf{1 0})\end{array}$ \\
Normal & $42(84.0)$ & $9(90.0)$ \\
Fair & $7(14.0)$ & $0(0.0)$ \\
Moderate & $0(0.0)$ & $0(0.0)$ \\
Severe & $1(2.0)$ & $1(10.0)$ \\
than the survivors $(10.0 \%$ versus 2.0\%) & \\
& \\
Disclable 6].
\end{tabular}

According to the findings of the current study, amphetamine abuse occurred mostly among individuals aged 21-40 years old (64.4\%), with fewer participants being $<20$ years old $(13.9 \%)$ or $>41$ years old $(21.7 \%)$. Other studies have shown that drug abuse is more prevalent among young people. ${ }^{9,10}$ Barooni et al. found that $18.5 \%$ of young adults who went to coffee shops in Tehran had a history of psychoactive drug abuse, in the form of ecstasy abuse. ${ }^{3}$ As with the present study, previous research has indicated that the mean age of drug abusers is low in Iran. ${ }^{11,12}$ A study of drug abuse cases in Taiwan reported a mean age of 26.7 years among those who abused drugs for the first time. ${ }^{13}$ In a study of methamphetamine-related fatalities in Australia, Kaye et al. found that the mean age of patients was 32.7 years and that $77 \%$ were male. ${ }^{14}$ In the current study, the vast majority of the subjects were male (85.2\%). Other researchers have also reported more frequent drug abuse practices among men. . $^{13,15,16}$

In the current study, approximately half of the patients exclusively used amphetamine and methamphetamine, while the rest used other drugs in combination with amphetamines. In addition, most patients administered the drugs via inhalation. Kaye et al. found that $89 \%$ of their subjects had used drugs other from methamphetamine, including benzodiazepines (41\%) and morphine (36\%). ${ }^{14}$ Moreover, administration of amphetamine is usually reported to be intravenous. ${ }^{14,17}$ In the current study, 10 patients $(4.3 \%)$ died after being admitted to the ICU, presumably due to drug-related toxicity. Knudsen et al. reported an amphetamine-related mortality rate of $12.3 \%$ among $\gamma$-hydroxybutyrate poisoning cases in Sweden. ${ }^{18}$

Troponin I and CK-MB levels were very high among amphetamine users in the present study, indicating 
cardiac damage; these findings were consistent with those of various previously published research. ${ }^{19-22}$ In a case report, Khattab et al. described a 54-year-old man with chest pains after amphetamine use, increased troponin I and CK-MB levels and complete obstruction of the left circumflex coronary artery due to acute thrombosis. ${ }^{23}$ The most commonly observed abnormal ECG findings in the current study were sinus tachycardia (43.0\%) and sinus tachycardia plus a prolonged QT interval (34.3\%). Haning et al. observed prolonged QT intervals among 27.2\% of patients abusing methamphetamines in the USA. ${ }^{24}$ Other researchers have reported various arrhythmias associated with the use of amphetamines or other psychoactive drugs, such as QT interval fluctuations, right bundle branch block and ST segment changes, particularly ST segment elevation. ${ }^{25-28}$ Westover et al. found a significant relationship between acute myocardial infarction and amphetamine abuse. ${ }^{29}$ Moreover, Kaye et al. found use of amphetamines to be associated with high pathological cardiac risk; however, this was possibly due to the presence of preexisting chronic disorders and hence not limited to amphetamine use. ${ }^{14}$

According to TTE findings in the current study, left ventricular systolic dysfunction was noted in three cases, abnormal EF in seven cases and abnormal ARD in 10 cases; additionally, right ventricle enddiastolic volume disorder was observed among both living and deceased patients admitted to the ICU. To the best of the authors' knowledge, no similar studies have been published in which amphetamine users were evaluated using echocardiographical parameters. However, various case reports have shown different cardiac abnormalities following abuse of amphetamine, such as reverse Takotsubo cardiomyopathy. $^{30}$ Yeo et al. reported that cardiomyopathy was related to methamphetamine use among young adults in Hawaii. ${ }^{31}$ Moreover, Wijetunga et al. found that $84 \%$ of crystal methamphetamine users had cardiomyopathy and global ventricular disorders. ${ }^{32}$ In another study, Maeno et al. found that methamphetamine use directly led to cellular hypertrophy and could potentially result in disorders of cardiac function among adult rats. ${ }^{33}$ Varner et al. demonstrated that methamphetamine administration could significantly change cardiovascular responses and lead to severe cardiac pathology; moreover, they also showed that methamphetamine elicited biphasic heart rate responses consisting of initial bradycardia followed by tachycardia. ${ }^{34}$ According to a review of methamphetamine-induced cardiac complications by
Paratz et al., dilated, hypertrophic and stress cardiomyopathies are the most common methamphetamine-associated cardiomyopathies. ${ }^{35}$ Additionally, intranasal administration of $\mathrm{d}$-amphetamine reportedly lead to a more rapid response compared with oral administration. ${ }^{5}$

This study is subject to certain limitations. Although the statistical significance of the findings in this study could not be determined due to the small sample size, these findings may pave the way for future research focusing on echocardiography findings among amphetamine users. Also, as there are few studies in the current literature on this topic, it was difficult to compare the findings of this study with those of previous research. In the current study, most of the subjects were referred to the hospital in the acute phase of drug abuse and the researchers did not have access to each patient's prior medical history relating to heart disease. As such, distinguishing heart problems due to drug abuse from those resulting from pre-existing cardiac disorders was not possible. In addition, most of the patients who were admitted did not consent to undergo echocardiography. Another limitation of this study was the lack of a control group with which to compare results. More studies are needed to assess the true pathogenicity of amphetamine abuse.

\section{Conclusion}

Although the majority of patients had normal TTE and ECG scans, cardiac complications were common among Iranian patients who abuse amphetamines, particularly sinus tachycardia and sinus tachycardia plus prolonged QT intervals. Emergency physicians should therefore be aware of these as potential cardiovascular complications of acute amphetamine abuse.

\section{ACKNOWLEDGEMENTS}

This study was based on findings from a thesis submitted to the Tehran University of Medical Sciences in 2015 (Giahchin L. Evaluation of cardiovascular complications of acute amphetamine abuse in Bahailoo Hospital: Cross-sectional study. Thesis, 2015, Tehran University of Medical Sciences, Tehran, Iran.)

\section{CONFLICT OF INTEREST}

The authors declare no conflicts of interest.

\section{FUNDING}

No funding was received for this study. 


\section{References}

1. Hoffman RS, Howland MA, Lewin NA, Nelson LS, Goldfrank LR. Goldfrank's Toxicologic Emergencies, 10th ed. New York, USA: McGraw-Hill, 2014. Pp. 2429-56.

2. Baheiraei A, Hamzehgardeshi Z, Mohammadi MR, Nedjat S, Mohammadi E. Alcohol and drug use prevalence and factors associated with the experience of alcohol use in Iranian adolescents. Iran Red Crescent Med J 2013; 15:212-17. doi: 10. 5812/ircmj.4022

3. Barooni Sh, Mehrdad R, Akbari E. [Survey of ecstasy use among 15-25 year-olds in five areas of Tehran]. Tehran Univ Med J 2008; 11:49-54.

4. DiMaio VJ, DiMaio D. Forensic Pathology, 2nd ed. Boca Raton, Florida, USA: CRC Press, 2001. Pp. 501-26.

5. Kirkpatrick MG, Gunderson EW, Johanson CE, Levin FR Foltin RW, Hart CL. Comparison of intranasal methamphetamine and d-amphetamine self-administration by humans. Addiction 2012; 107:783-91. doi: 10.1111/j.13600443.2011.03706.x

6. Shannon MW, Borron SW, Burns MJ. Haddad and Winchester's Clinical Management of Poisoning and Drug Overdose, 4th ed. Amsterdam, Netherlands: Saunders, 2007. P. 782

7. Karch SB, Drummer O. Karch's Pathology of Drug Abuse, 4th ed. Boca Raton, Florida, USA: CRC Press, 2008. Pp. 261-312.

8. Simonson E, Cady LD Jr, Woodbury M. The normal Q-T interval. Am Heart J 1962; 63:747-53. doi: 10.1016/00028703(62)90059-5.

9. Gonzales R, Mooney L, Rawson RA. The methamphetamine problem in the United States. Annu Rev Public Health 2010; 31:385-98. doi: 10.1146/annurev.publhealth.012809.103600.

10. McKetin R, Kozel N, Douglas J, Ali R, Vicknasingam B, Lund $\mathrm{J}$, et al. The rise of methamphetamine in Southeast and East Asia. Drug Alcohol Rev 2008; 27:220-8. doi: 10.10 80/09595230801923710

11. Momtazi S, Rawson R. Substance abuse among Iranian high school students. Curr Opin Psychiatry 2010; 23:221-6. doi: 10.1097/YCO.0b013e328338630d.

12. Amiri ZM, Shakib AJ, Moosavi AK. Prevalence and risk factors of ecstasy use among college students in Astara, Islamic Republic of Iran. East Mediterr Health J 2009; 15:1192-200.

13. Hsu J, Lin JJ, Tsay WI. Analysis of drug abuse data reported by medical institutions in Taiwan from 2002 to 2011. J Food Drug Anal 2014; 22:169-77. doi: 10.1016/j.jfda.2014.01.019.

14. Kaye S, Darke S, Duflou J, McKetin R. Methamphetamine区 related fatalities in Australia: Demographics, circumstances, toxicology and major organ pathology. Addiction 2008; 103:1353-60. doi: 10.1111/j.1360-0443.2008.02231.x.

15. Vollenweider FX, Liechti ME, Gamma A, Greer G, Geyer M Acute psychological and neurophysiological effects of MDMA in humans. J Psychoactive Drugs 2002; 34:171-84. doi: 10.1080/ 02791072.2002 .10399951

16. Becker JB, Hu M. Sex differences in drug abuse. Front Neuroendocrinol 2008; 29:36-47. doi: 10.1016/j.yfrne.2007. 07.003 .

17. Kaye S, McKetin R, Duflou J, Darke S. Methamphetamine and cardiovascular pathology: A review of the evidence. Addiction 2007; 102:1204-11. doi: 10.1111/j.1360-0443.2007.01874.x.

18. Knudsen K, Greter J, Verdicchio M. High mortality rates among GHB abusers in Western Sweden. Clin Toxicol (Phila) 2008; 46:187-92. doi: 10.1080/15563650701263633.

19. Pozoga J, Snopek G, Dabrowski M. [Acute coronary syndrome after amphetamine use in a young male with myocardial bridging: A case report]. Kardiol Pol 2005; 62:381-2.
20. Chen JP. Methamphetamine-associated acute myocardial infarction and cardiogenic shock with normal coronary arteries: Refractory global coronary microvascular spasm. J Invasive Cardiol 2007; 19:E89-92.

21. Brennan K, Shurmur S, Elhendy A. Coronary artery rupture associated with amphetamine abuse. Cardiol Rev 2004; 12:282-3. doi: 10.1097/01.crd.0000132372.38506.45.

22. Wang Q, Michiue T, Ishikawa T, Zhu BL, Maeda H. Combined analyses of creatine kinase $\mathrm{MB}$, cardiac troponin $\mathrm{I}$ and myoglobin in pericardial and cerebrospinal fluids to investigate myocardial and skeletal muscle injury in medicolegal autopsy cases. Legal Med (Tokyo) 2011; 13:226-32. doi: 10.1016/j. legalmed.2011.05.002.

23. Khattab E, Shujaa A. Amphetamine abuse and acute thrombosis of left circumflex coronary artery. Int J Case Rep Imag 2013; 4:698-701. doi: 10.5348/ijcri-2013-12-414-CR-8.

24. Haning W, Goebert D. Electrocardiographic abnormalities in methamphetamine abusers. Addiction 2007; 102:70-5. doi: 10.1111/j.1360-0443.2006.01776.x.

25. Sinha A, Lewis O, Kumar R, Yeruva SL, Curry BH. Amphetamine abuse related acute myocardial infarction. Case Rep Cardiol 2016; 2016:7967851. doi: 10.1155/2016/7967851.

26. Samuels SI, Maze A, Albright G. Cardiac arrest during Cesarean section in a chronic amphetamine abuser. Anesth Analg 1979; 58:528-30. doi: 10.1213/00000539-197911000-00021.

27. Awudu GA, Besag FM. Cardiovascular effects of methylphenidate, amphetamines and atomoxetine in the treatment of attention-deficit hyperactivity disorder: An update. Drug Saf 2014; 37:661-76. doi: 10.1007/s40264-0140201-8.

28. Chia-Yu Chang J, Peng CZ, How CK, Huang MS. An unusual case of silent acute ST-elevation myocardial infarction following amphetamine use. Pak J Med Sci 2013; 29:1059-61. doi: $10.12669 /$ pjms.294.3500.

29. Westover AN, Nakonezny PA, Haley RW. Acute myocardial infarction in young adults who abuse amphetamines. Drug Alcohol Depend 2008; 96:49-56. doi: 10.1016/j.drugalcdep. 2008.01.027.

30. Movahed MR, Mostafizi K. Reverse or inverted left ventricular apical ballooning syndrome (reverse Takotsubo cardiomyopathy) in a young woman in the setting of amphetamine use. Echocardiography 2008; 25:429-32. doi: 10.1111/j.1540-8175.2007.00604.x.

31. Yeo KK, Wijetunga M, Ito H, Efird JT, Tay K, Seto TB, et al. The association of methamphetamine use and cardiomyopathy in young patients. Am J Med 2007; 120:165-71. doi: 10.1016/j. amjmed.2006.01.024.

32. Wijetunga M, Seto T, Lindsay J, Schatz I. Crystal methamphetamine-associated cardiomyopathy: Tip of the iceberg? J Toxicol Clin Toxicol 2003; 41:981-6. doi: 10.1081/ CLT-120026521

33. Maeno $Y$, Iwasa M, Inoue $H$, Koyama H, Matoba R, Nagao M. Direct effects of methamphetamine on hypertrophy and microtubules in cultured adult rat ventricular myocytes. Forensic Sci Int 2000; 113:239-43. doi: 10.1016/S0379-0738 (00)00216-4

34. Varner KJ, Ogden BA, Delcarpio J, Meleg-Smith S. Cardiovascular responses elicited by the "binge" administration of methamphetamine. J Pharmacol Exp Ther 2002; 301:152-9. doi: $10.1124 /$ jpet.301.1.152

35. Paratz ED, Cunningham NJ, MacIsaac AI. The cardiac complications of methamphetamines. Heart Lung Circ 2016; 25:325-32. doi: 10.1016/j.hlc.2015.10.019. 